\title{
Comparison of the demographic parameters and survival of two phenotypes of Harmonia axyridis (Coleoptera: Coccinellidae)
}

\author{
ELENi ZEKI ${ }^{1}$, Nikos E. PAPANIKOLAOU ${ }^{1, *}$, Nikos DEMIRIS ${ }^{2}$ and Dimitrios C. KONTODIMAS ${ }^{1}$ \\ ${ }^{1}$ Benaki Phytopathological Institute, St. Delta 8, 14561, Kifissia, Greece; e-mails: nepapanikolaou@yahoo.gr; e.zeki@dionet.gr; \\ d.kontodimas@bpi.gr \\ ${ }^{2}$ Department of Statistics, Athens University of Economics and Business, Patission 76, 10434, Athens, Greece; \\ e-mail: nikos.demiris@gmail.com
}

Key words. Coleoptera, Coccinellidae, Harmonia axyridis, succinea morph, spectabilis morph, bootstrap, life tables, survival curves

\begin{abstract}
This paper reports the results of a comparative study of the demographic parameters of two phenotypes of Harmonia axyridis Pallas, reared on the black bean aphid, Aphis fabae Scopoli at $25 \pm 1{ }^{\circ} \mathrm{C}, 65 \pm 2 \% \mathrm{RH}$ and a photoperiod of 16L : 8D. The values of the intrinsic rate of increase and the finite rate of increase, which were obtained by bootstrapping, were greater for the succinea morph ( $0.182 \mathrm{females} / \mathrm{female} / \mathrm{d}$ and 1.200 , respectively) than the spectabilis morph ( 0.168 females/female/d and 1.183 , respectively). The net reproductive rates and mean generation times of the two morphs did not differ. The risk of death of the succinea morph was significantly greater. However, there was no significant difference between the estimated survival times. Mean survival times were $95.2 \mathrm{~d}$ and 89.3 $\mathrm{d}$ for the spectabilis and succinea morphs, respectively.
\end{abstract}

\section{INTRODUCTION}

Predaceous coccinellids are common biological control agents of insect pests, preying principally on hemipterous insects, such as aphids and coccids (Dixon, 2000; Hodek et al., 2012). Within a season aphidophagous coccinellidae can suppress several aphid pests in agroecosystems (Obrycki et al., 2009). Harmonia axyridis (Pallas) is a polyphagous predator, preying on aphids, coccids, psyllids and other insect prey (Hodek et al., 2012). Augmentative releases of $H$. axyridis have been used to control aphid populations in several regions in Europe and U.S.A, because this species is a voracious predator of aphids (Roy \& Wajnberg, 2008). However, Ware \& Majerus (2008) alleged that $H$. axyridis is an intraguild predator of several ladybird species and there are a number of studies that indicate $H$. axyridis is a strong asymmetrical intraguild predator of other guild members (Pell et al., 2008, Nedved et al., 2013). The relatively large size and aggressive behaviour of $H$. axyridis contributes to its success as an intraguild predator, while the defensive chemistry of adults makes them unpalatable to other coccinellids (Hough-Goldstein et al., 1996) and the adults are protected against bird predators due to their colouration (Pruchova et al., 2014).

Several phenotypes of $H$. axyridis are described, which are controlled by 15 alleles, with most of the phenotypes rare in nature (Tan, 1946). The four major morphs are succinea, which has a reddish or brownish ground colour, and the melanic group that includes the morphs conspicua, spectabilis and aulica (Soares et al., 2001). Phenotypic variation in $H$. axyridis has been shown to be associated with several biological features of the coccinellid, such as fecundity, fertility, maximum body-weight and the duration of the egg and pre-pupal stages (Soares et al., 2001), as well as its predatory activity (Soares et al., 2003). Demographic analysis of insect populations is essential for determining their fitness components. The outcome of this analysis is often summarized in several parameters, such as the intrinsic rate of increase, which is an estimate of the potential rate of increase of a population and used when selecting a biological control agent (Kontodimas et al., 2007). In this study we compare the demography and survival of the succinea and spectabilis morphs of $H$. axyridis, fed on the black bean aphid, Aphis fabae (Scopoli), which is a major pest of cultivated plants (Blackman \& Eastop, 2000).

\section{MATERIAL AND METHODS}

\section{Insect culture and experimental set-up}

This study was conducted on the invasive succinea and spectabilis morphs of $H$. axyridis, which are now established in the UK. The coccinellids were reared on $A$. fabae infesting potted fava bean, Vicia faba L., plants at $25 \pm 1{ }^{\circ} \mathrm{C}, 65 \pm 2 \% \mathrm{RH}$ and a photoperiod of $16 \mathrm{~L}: 8 \mathrm{D}$ in large cylindrical Plexiglass cages $(50 \times 30$ $\mathrm{cm})$. An A. fabae colony originally from a stock colony at the Biological Control Laboratory, Benaki Phytopathological Institute was reared on $V$. faba plants at $20 \pm 1{ }^{\circ} \mathrm{C}(65 \pm 2 \% \mathrm{RH}, 16 \mathrm{~L}: 8 \mathrm{D})$.

Egg masses of succinea and spectabilis morphs were transferred from the stock culture into cylindrical Plexiglass cages (10 $\mathrm{cm}$ diameter $\times 5 \mathrm{~cm}$ height). After hatching, larvae were kept individually with an abundance of $A$. fabae nymphs and adults in cylindrical Plexiglass cages $(10 \mathrm{~cm}$ diameter $\times 5 \mathrm{c} \mathrm{m}$ height $)$. The survival and the duration of development of the immature stages were recorded every $24 \mathrm{~h}$, using 27 and 24 newly emerged larvae of each morph.

Female longevity and fecundity was determined using 26 and 23 newly emerged pairs of adults of succinea and spectabilis morphs, respectively, which were kept in cylindrical Plexiglass cages $(10 \mathrm{~cm}$ diameter $\times 5 \mathrm{~cm}$ height). The observations were made every $24 \mathrm{~h}$.

\section{Statistical analysis}

The data on the generation cycle duration and female fecundity were examined via the Shapiro-Wilk normality test which in the case of the generation cycle duration data indicated departure from a normal distribution. Therefore, fecundity data were

\footnotetext{
* Corresponding author.
} 
TABLE 1. Values of net reproductive rate $\left(R_{0}\right)$, intrinsic rate of increase $\left(r_{m}\right)$, finite rate of increase $(\lambda)$, mean generation time $(T)$ and doubling time $(D T)$ of two morphs of $H$. axyridis reared on $A$. fabae (mean, $95 \%$ Confidence Intervals).

\begin{tabular}{|c|c|c|c|c|c|c|c|c|c|c|}
\hline & \multirow{2}{*}{\multicolumn{2}{|c|}{$\begin{array}{c}\text { Net reproductive rate } \\
\text { (females/female) } \\
R_{0}=\sum\left(l_{x} \times m_{x}\right)\end{array}$}} & \multirow{2}{*}{\multicolumn{2}{|c|}{$\begin{array}{l}\text { Intrinsic rate of increase } \\
\text { (females/female/day) } \\
\sum\left(e^{r_{m} \times x} \times l_{x} \times m_{x}\right)=1\end{array}$}} & \multirow{2}{*}{\multicolumn{2}{|c|}{$\begin{array}{l}\text { Finite rate } \\
\text { of increase } \\
\qquad \lambda=e^{r_{m}}\end{array}$}} & \multirow{2}{*}{\multicolumn{2}{|c|}{$\begin{array}{c}\text { Mean generation } \\
\text { time (days) } \\
T=\frac{\ln R_{0}}{r_{m}}\end{array}$}} & \multirow{2}{*}{\multicolumn{2}{|c|}{$\begin{array}{l}\text { Doubling time } \\
\quad \text { (days) } \\
D T=\frac{\ln 2}{r_{m}}\end{array}$}} \\
\hline & & & & & & & & & & \\
\hline & Mean & $95 \%$ C.I. & Mean & 95\% C.I. & Mean & 95\% C.I. & Mean & $95 \%$ C.I. & Mean & $95 \%$ C.I. \\
\hline Spectabilis morph & 607 & $516-696$ & 0.168 & $0.158-0.177$ & 1.183 & $1.171-1.193$ & 38.15 & $36.37-40.12$ & 4.13 & $3.92-4.39$ \\
\hline Succinea morph & 758 & $656-853$ & 0.182 & $0.178-0.188$ & 1.200 & $1.194-1.206$ & 36.28 & $35.31-37.31$ & 3.79 & $3.69-3.90$ \\
\hline
\end{tabular}

analyzed using a t-test and that for the duration of the generation cycle using a Mann-Whitney test $(\alpha=0.05)$. The KaplanMeier method was used to estimate the survival curves of the two morphs. In addition, the Kaplan-Meier estimate was used to derive the mean survival times and their $95 \%$ confidence intervals This analysis was done using SigmaPlot (Systat Software, 2008).

The following demographic parameters were calculated for each $H$. axyridis morph (Kontodimas et al., 2007; Papanikolaou et al., 2014): cohort survival to age $x$; age specific mortality; age specific fecundity, which is the mean number of eggs multiplied by the ratio $q /\left(q+\bigcirc^{\top}\right)$ (recorded for 150-200 offspring); net reproductive rate; intrinsic rate of increase; finite rate of increase; mean generation time; doubling time. Significant differences between demographic parameters were tested via the superposition of $95 \%$ confidence intervals (Wald test), which were obtained by bootstrapping in R (R Development Core Team, 2010). In particular, for each treatment we sampled ten thousand individuals in order to obtain the $95 \%$ confidence intervals.

\section{RESULTS}

The comparison of the estimated demographic parameters of the two morphs of $H$. axyridis revealed similarities and differences (Table 1). The net reproductive rate of spectabilis ( 607 females per female) and succinea ( 758 females per female) did not differ. Also, there was no difference in the estimated mean generation times of the two morphs (38.15 and $36.28 \mathrm{~d}$ for spectabilis and succinea, respectively). In contrast, the intrinsic rate of increase of succinea ( 0.182 females per female per day) was greater than that of spectabilis ( 0.168 females per female per day). As a consequence, the finite rate of increase was greater and the doubling time shorter for succinea (1.200 and $3.79 \mathrm{~d}$, respectively) than spectabilis (1.183 and $4.13 \mathrm{~d}$, respectively) morph.

The biological features of the $H$. axyridis morphs are presented in Table 2. The generation cycle of succinea ( $23.5 \mathrm{~d})$ was shorter than that of spectabilis $(25.5 \mathrm{~d})$. The fecundity of succinea (1480 eggs per female) was significantly greater than that of spectabilis (1197 eggs per female).

The risk of death of succinea was significantly greater than that of spectabilis $\left(\chi^{2}[\log\right.$ rank $]=4.706 ; \mathrm{df}=1 ; P=0.030$; Fig. 1).

TABLE 2. Generation cycle (median), survival time (mean, S.E.) and fecundity (mean, S.E.) of two morphs of Harmonia axyridis Pallas (Coleoptera: Coccinellidae) fed on Aphis fabae Scopoli (Hemiptera: Aphididae), under constant conditions $\left(25 \pm 1^{\circ} \mathrm{C}, 65\right.$ $\pm 2 \% \mathrm{RH} ; 16 \mathrm{~L}: 8 \mathrm{D})$.

\begin{tabular}{lccc}
\hline & $\begin{array}{c}\text { Generation } \\
\text { cycle (days) }\end{array}$ & $\begin{array}{c}\text { Survival time } \\
\text { (days) }\end{array}$ & $\begin{array}{c}\text { Fecundity } \\
\text { (eggs/female) }\end{array}$ \\
\hline Spectabilis morph & $26.0 \mathrm{a}$ & $95.2 \pm 4.7 \mathrm{a}$ & $1197 \pm 74 \mathrm{a}$ \\
Succinea morph & $24.0 \mathrm{~b}$ & $89.3 \pm 4.1 \mathrm{a}$ & $1480 \pm 80 \mathrm{~b}$ \\
\hline
\end{tabular}

Medians or means followed by the same letter are not significantly different.
However, there was no significant difference between the estimated survival times, based on the $95 \%$ CI criterion (Table 2). Thus, mean survival times were $95.2 \mathrm{~d}$ and $89.3 \mathrm{~d}$ for the spectabilis and succinea morphs, respectively.

\section{DISCUSSION}

Our study provides evidence that phenotype is associated with differences in the performance of $H$. axyridis. A similar result is reported by Soares et al. (2001), as they state that the fecundity of the melanic morph aulica is greater than that of the black morph nigra. Also, in a recent review (Sloggett \& Honek, 2012) the authors note that colour morphs of $H$. axyridis can differ in several characters that determine fitness, and some observations in natural conditions (Osawa \& Nishida, 1992; Wang et al., 2009) suggest that red morphs have a greater fecundity and black morphs higher survival. However, here we focused on life table statistics, which are associated with population growth rate. Tabulating the survivorship and fecundity schedules of individuals from birth to death, we showed that the values of the intrinsic and the finite rates of increase were greater and the doubling time shorter for the succinea morph, indicating that its potential population growth rate is greater than that of spectabilis. This is due to the shorter generation cycle and greater fecundity of succinea, although its risk of death was significantly greater than that of the spectabilis morph. However, the net reproductive rate and, therefore, the mean generation time, which represents the average time for a population to increase by a factor equal to the net reproductive rate (Borges et al., 2013), of the two morphs studied did not differ. This result is biologically interpretable, since the

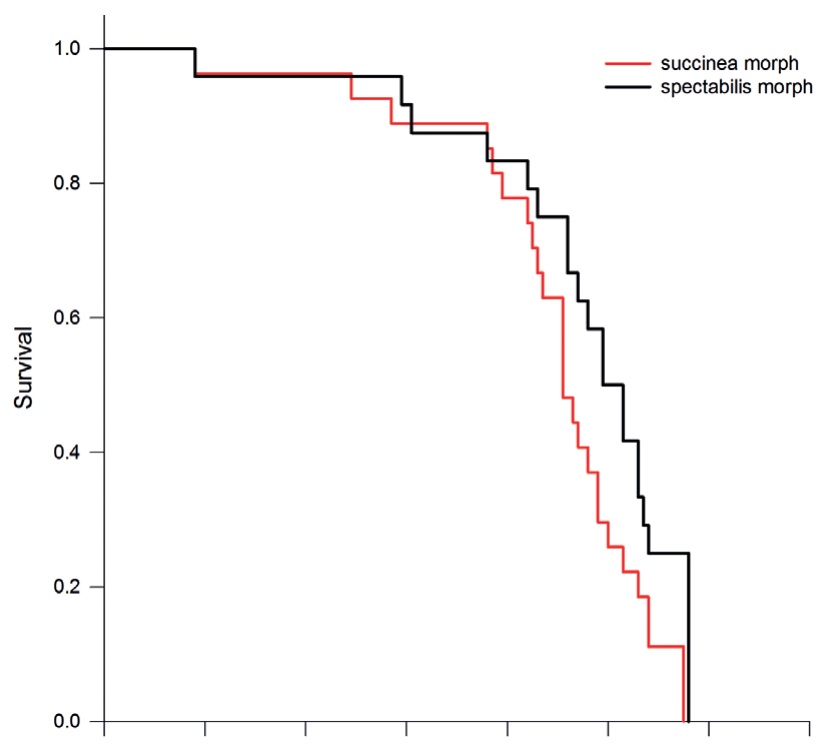

Fig. 1. Survival curves of two morphs of Harmonia axyridis reared on Aphis fabae. 
net reproductive rate depends on cohort survival, which is lower, and fecundity, which is greater for the succinea morph.

The fact that there is a marginally significant difference in the survival curves but not in mean survival may appear somewhat surprising. However, a careful inspection of the complete survival curves reveals the nature of this disparity. In particular, it is immediately apparent that the two curves are virtually identical for the initial two thirds of their course. After approximately 80 days, more of the spectabilis morph survived, thus leading to the difference in the log-rank test. However, this latter part of the curve represents a relatively small contribution to mean survival, which is not significantly different in the two morphs.

As in our study, the life tables of the aphidophagous coccinellids Coccinella septempunctata L., Ceratomegilla undecimnotata (Schneider) and Propylea quatuordecimpunctata L., fed on A. fabae were determined by Kontodimas et al. (2008). A comparison of their results with ours showed that the greatest value of the intrinsic rate of increase and shortest doubling time was recorded for the succinea morph. In contrast, the spectabilis morph has a similar potential population increase to $P$. quatuordecimpunctata $\left(r_{m}=0.166\right.$ females/female/day, $D T=4.2$ days $)$ and a greater one than $C$. septempunctata $\left(r_{m}=0.118\right.$ females/female/day, $D T=5.9$ days) and C. undecimnotata $\left(r_{m}=0.142\right.$ females/female/day, DT $=4.8$ days). These characteristics are thought to account for the invasive ability of $H$. axyridis and its great effectiveness as an intraguild predator. In addition, Lanzoni et al. (2004) and Castro et al. (2011) report lower values of the intrinsic rate of increase in H. axyridis fed on Myzus persicae (Sulzer) and Cinara atlantica (Wilson), respectively. In general, variation in life table parameters may result from feeding the predators on different aphids or on the same aphid fed on different host plants (e.g. Papachristos \& Papadopoulos, 2009; Ungerova et al., 2010). In addition, Ungerova et al. (2010) report the suitability of several aphid species (Acyrthosiphon pisum, A. fabae, A. ignotum, A. philadelphi, A. sambuci, A. spiraephaga, Dysaphis plantaginea, Hyadaphis tataricae, Rhopalosiphum padi) and conspecific eggs as prey for $H$. axyridis, concluding that $A$. philadelphi and $A$. fabae are the most suitable prey, conspecific eggs moderately suitable, whereas $A$. sambuci is a less suitable prey.

We cannot exclude that the colour type is associated with the differences recorded for the two laboratory lines. However, the results of our study indicate differences in this coccinellid's performance are associated with differences in colour. In addition, biological features and demographic parameters of the $H$. axyridis morphs tested in this study may be incorporated into prey-predator models evaluating the population dynamics of these organisms, or mass-rearing models allowing for efficient coccinellid breeding in an insectary (Carey \& Vargas, 1985).

ACKNOWLEDGEMENTS. We are grateful to the late M.E.N Majerus for providing us with the Harmonia axyridis strains.

\section{REFERENCES}

Blackman R.L. \& Eastop V.F. 2000: Aphids on the World's Crops. An Identification and Information Guide. 2nd ed. John Wiley \& Sons, Chichester, $476 \mathrm{pp}$.

Borges I., Hemptinne J.L. \& Soares A.O. 2013: Contrasting population growth parameters of the aphidophagous Scymnus nubilus and the coccidophagous Nephus reunioni. - BioControl 58: $351-357$.

CAREY J.R. \& VARgas R. 1985: Demographic analysis of insect mass rearing: case study of three tephritids. $-J$. Econ. Entomol. 78: 523-527.

Castro C.F., Almeida L.M. \& Penteado S.R.C. 2011: The impact of temperature on biological aspects and life table of Harmonia axyridis (Pallas) (Coleoptera: Coccinellidae). — Fla Entomol. 94: 923-932.

Dixon A.F.G. 2000: Insect Predator-Prey Dynamics: Ladybird Beetles and Biological Control. Cambridge University Press, Cambridge, $257 \mathrm{pp}$.

Hodek I., van EMden H.F \& HonĚK A. 2012: Ecology and Behaviour of the Ladybird Beetles (Coccinellidae). WileyBlackwell, Chichester, 600 pp.

Hough-Goldstein J., Cox J. \& Armstrong A. 1996: Podisus maculiventris (Hemiptera: Pentatomidae) predation on ladybird beetles (Coleoptera: Coccinellidae). — Fla Entomol. 79: 6468.

Kontodimas D.C., Milonas P.G., Stathas G.J., Economou K.P. \& Kavallieratos N.G. 2007: Life table parameters of the pseudococcid predators Nephus includens and Nephus bisignatus (Coleoptera: Coccinellidae). — Eur. J. Entomol. 104: 407-415.

Kontodimas D.C., Milonas P.G., Stathas G.J., Papanikolaou N.E., Skourti A. \& Matsinos Y.G. 2008: Life table parameters of the aphid predators Coccinella septempunctata, Ceratomegilla undecimnotata and Propylea quatuordecimpunctata (Coleoptera: Coccinellidae). - Eur. J. Entomol. 105: 427-430.

Lanzoni A., Accinelli G., Bazzocchi G.G. \& Burgio G. 2004: Biological traits and life table of the exotic Harmonia axyridis compared with Hippodamia variegata, and Adalia bipunctata (Col., Coccinellidae). - J. Appl. Entomol. 128: 298-306.

Nedved O., Fols X., Ungerova D. \& Kalushrov P. 2013: Alien vs. predator - the native lacewing Chrysoperla carnea is the superior intraguild predator in trials against the invasive ladybird Harmonia axyridis. - Bull. Insectol. 66: 73-78.

Obrycki J.J., Harwood J.D., Kring T.J. \& O’NeIl R.J. 2009; Aphidophagy by Coccinellidae: Application of biological control in agroecosystems. - Biol. Contr. 51: 244-254.

OsaWA N. \& Nishida T. 1992: Seasonal variation in elytral colour polymorphism in Harmonia axyridis (the ladybird beetle), the role of non-random mating. - Heredity 69: 297-307.

Papachristos D.P. \& Papadopoulos N.T. 2009: Are citrus species favourable hosts for the Mediterranean fruit fly? A demographic perspective. - Entomol. Exp. Appl. 132: 1-12.

Papanikolaou N.E., Milonas P.G., Kontodimas D.C., Demiris N. \& Matsinos Y.G. 2014: Life table analysis of Propylea quatuordecimpunctata (Coleoptera: Coccinellidae) at constant temperatures. - Ann. Entomol. Soc. Am. 107: 158-162.

Pell J.K., Baverstock J., Roy H.E., Ware R.L. \& Majerus M.E.N. 2008: Intraguild predation involving Harmonia axyridis: a review of current knowledge and future perspectives. BioControl 53: 147-168.

Pruchova A., Nedved O., Vesely P., Ernestova B. \& Fuchs R. 2014: Visual warning signals of the ladybird Harmonia axyridis: the avian predators' point of view. - Entomol. Exp. Appl. 151: 128-134.

R Development Core Team 2010: R: A Language and Environment for Statistical Computing. R foundation for statistical computing, Vienna, Austria. URL http://www.R-project.org.

Roy H. \& WaJNBerg E. 2008: From biological control to invasion: the ladybird Harmonia axyridis as a model species. BioControl 53: 1-4.

Sloggett J.J. \& HoNĚK A. 2012: Genetic studies. In Hodek I., van Emden H.F. \& HonĚK A. (eds): Ecology and Behaviour of the Ladybird Beetles (Coccinellidae). Wiley-Blackwell, Chichester, pp. 13-53.

Soares A.O., Coderre D. \& Schanderl H. 2001: Fitness of two phenotypes of Harmonia axyridis. - Eur. J. Entomol. 98: 287-293.

Soares A.O., Coderre D. \& Schanderl H. 2003: Effect of temperature and intraspecific allometry on predation by two phe- 
notypes of Harmonia axyridis Pallas (Coleoptera: Coccinellidae). — Environ. Entomol. 32: 939-944.

Systat Software 2008: SigmaPlot for Vindows. Version 11.0.

TAN C.C. 1946: Mosaic dominance in the inheritance of color patterns in the lady-bird beetle, Harmonia axyridis. — Genetics 31: 195 .

Ungerova D., Kalushrov P. \& Nedved O. 2010: Suitability of diverse prey species for development of Harmonia axyridis and the effect of container size. - IOBC-WPRS Bull. 58: 165-174.
Wang S., Michaud J.P., Zhang R.Z., Zhang F. \& LiU S. 2009: Seasonal cycles of assortative mating and reproductive behavior in polymorphic populations of Harmonia axyridis in China. - Ecol. Entomol. 34: 483-494.

Ware R. L. \& MaJerus M.E.N. 2008: Intraguild predation of immature stages of British and Japanese coccinellids by the invasive ladybird Harmonia axyridis. — BioControl 53: 169-188.

Received April 28, 2014; revised and accepted August 13, 2014 Prepublished online October 16, 2014 